\title{
A comparison of slurry erosion characteristics of TiNi shape memory alloys and SUS304 stainless steel
}

\author{
H.C. Lin $^{\mathrm{a}}$, S.K. Wu ${ }^{\mathrm{b}, *}$, C.H. Yeh ${ }^{\mathrm{a}}$ \\ a Department of Materials Science, Feng Chia University, Taichung 407, Taiwan, ROC \\ ${ }^{\mathrm{b}}$ Department of Mechanical Engineering and Institute of Materials Science and Engineering, National Taiwan University, Taipei 106, Taiwan, ROC
}

Received 18 July 2000; received in revised form 26 March 2001; accepted 2 April 2001

\begin{abstract}
The slurry erosion characteristics of three TiNi shape memory alloys and SUS304 stainless steel using the liquid/solid impingement have been systematically studied. Experimental results show that more resistant TiNi alloys and less resistant SUS304 stainless steel exhibit ductile behavior and the maximum erosion has observed at $30^{\circ}$. The surface morphologies exhibit many long furrows and ridges at low impingement angles. The exponent in the relation $\varepsilon=k V^{n}$ varied between 2 and 3 for impingement angles between $15^{\circ}$ and $90^{\circ}$. Work hardening of surface is observed on the surface of all tested materials. The work hardening layer and thin platelet formation increase with angle of impingement. The SIM formation and pseudoelastic behavior of TiNi B2 phase, and variant accommodation and SIP formation of TiNi martensite, make important contributions to the slurry erosion resistance of TiNi alloys. (C) 2001 Elsevier Science B.V. All rights reserved.
\end{abstract}

Keywords: Liquid/solid impingement erosion; TiNi alloys; SUS304 stainless steel; Thermoelastic martensitic transformation

\section{Introduction}

TiNi alloys are considered as the most important shape memory alloys (SMAs) because of their many applications based on the shape memory effect (SME) and pseudoelasticity (PE) [1-3]. TiNi alloys have superior properties in ductility, fatigue strength [4], corrosion resistance [5], biocompatibility [6] and recoverable strain [1]. It is also well known that TiNi alloys can exhibit high mechanical damping because of the easy movement of twin boundaries [7,8]. They also show excellent wear resistance resulting from their pseudoelastic behavior and hardening phenomenon [9-12]. In addition to these functional properties, TiNi alloys have recently been found to exhibit good slurry resistance [13], water jet erosion resistance [14] and cavitation erosion resistance $[15,16,19]$ all attributable to their unique properties of martensite-variants accommodation, pseudoelasticity and high work-hardening rates. Hence, TiNi alloys can become a new type of tribo-material in some pioneering applications. The turbine blades, needle and nozzle in hydraulic machinery have to tolerate perpetual high-speed water (with or without solid particles) impingement, and hence they must have excellent strength, toughness and erosion resis-

\footnotetext{
* Corresponding author. Tel.: +886-2-2363-7846; fax: +886-2-2363-4562.

E-mail address: skw@ccms.ntu.edu.tw (S.K. Wu).
}

tance. However, the erosion resistance of conventional turbine blades, made of low-carbon steel, low-manganese steel, stainless steel, white cast iron or plastic resin, is very low. These turbine blades are easily damaged under high-speed water (with or without solid particles) impingement, thus interrupting hydraulic power generation. Hence, it is important to develop more erosion-resistant materials. In fact, TiNi alloys are considered to have excellent erosion resistance due to their reversible transformation characteristics [17-19], high work-hardening rates [18-22] and high resistance to low-cycle fatigue $[15,23]$, making them be potential candidates in hydraulic machinery. However, our understanding in this area is incomplete. No systematic investigation has been reported on the erosion properties of TiNi alloys. In the present study, we aim to investigate the slurry erosion characteristics of TiNi alloys by using the liquid/solid impingement erosion tests. Meanwhile, the SUS304 stainless steel (commercially available) is also studied for comparison.

To investigate the liquid/solid impingement erosion of TiNi alloys, it is helpful to first understand some important metallurgical properties of these alloys. Table 1 presents the transformation temperatures, hardness, elongation and crystal structures at room temperature for $\mathrm{Ti}_{49} \mathrm{Ni}_{51}, \mathrm{Ti}_{50} \mathrm{Ni}_{50}$ and $\mathrm{Ti}_{50} \mathrm{Ni}_{40} \mathrm{Cu}_{10}$ alloys. In addition, the hardness, elongation and crystal structure of SUS304 stainless steel are also presented in Table 1 for comparison. It can be seen that TiNi alloys and SUS304 stainless steel have similar 
Table 1

Transformation temperatures, hardness, elongation and crystal structure of TiNi alloys and SUS304 stainless steel ${ }^{\mathrm{a}}$

\begin{tabular}{lcccc}
\hline Alloy & $M^{*}\left({ }^{\circ} \mathrm{C}\right)$ & $A^{*}\left({ }^{\circ} \mathrm{C}\right)$ & Hardness $(\mathrm{Hv})$ & Elongation $(\%)$ \\
\hline $\mathrm{Ti}_{49} \mathrm{Ni}_{51}$ & -104 & -60 & 293 & 23 \\
$\mathrm{Ti}_{50} \mathrm{Ni}_{50}$ & 35 & 79 & 214 & 25 \\
$\mathrm{Ti}_{50} \mathrm{Ni}_{40} \mathrm{Cu}_{10}$ & $47(\mathrm{~B} 2 \rightarrow \mathrm{B} 19)$ & $70(\mathrm{~B} 19 \rightarrow \mathrm{B} 2)$ & 181 & $\mathrm{~B} 2$ parent phase \\
& $6\left(\mathrm{~B} 19 \rightarrow \mathrm{B} 19^{\prime}\right)$ & $22\left(\mathrm{~B} 19^{\prime} \rightarrow \mathrm{B} 19\right)$ & & $\mathrm{B} 19^{\prime}$ martensite \\
$\mathrm{SUS304}$ & - & - & 246 & $\mathrm{~B} 19, \mathrm{~B} 19^{\prime}$ \\
\hline
\end{tabular}

${ }^{\text {a }} M^{*}$ and $A^{*}$ are the peak temperatures of DSC curves for the forward and reversed martensitic transformation of TiNi shape memory alloys, respectively.

hardness of about $180-280 \mathrm{Hv}$ and elongation of about $23-27 \%$ at a strain rate of $10^{-2} / \mathrm{s}$. However, it is interesting to find, as presented in Section 3, that TiNi alloys exhibit a better erosion resistance than the SUS304 stainless steel. Hence, in addition to hardness and elongation, other metallurgical properties, such as phase transformations, work-hardening rate and resistance to fatigue, will also have important influence on the erosion characteristics of TiNi alloys. It is well known that the variants of TiNi martensite can be preferentially reoriented to accommodate the deformation strain [1-3]. Meanwhile, the pseudoelastic behavior originating from the stress-induced martensitic (SIM) transformation of the parent B2 phase can enhance the elastic contribution and reduce the plastic deformation. In our previous study [16], the stress-strain curves of TiNi alloys were found to exhibit a high work-hardening rate. This indicates that the quantity of effective impact of higher stress level to cause the erosion damage should become smaller during the further impact. All these unique properties of TiNi alloys are considered to have important influence on their liquid/solid impingement erosion resistance.

\section{Experimental procedure}

The conventional tungsten arc-melting technique was employed to prepare the $\mathrm{Ti}_{49} \mathrm{Ni}_{51}, \mathrm{Ti}_{50} \mathrm{Ni}_{50}$ and $\mathrm{Ti}_{50} \mathrm{Ni}_{40} \mathrm{Cu}_{10}$ alloys (in at.\%). Titanium (purity 99.7\%), nickel (purity $99.98 \%$ ) and copper (purity 99.98\%), totaling about $200 \mathrm{~g}$, were melted and remelted at least six times in an argon atmosphere. Pure titanium buttons were also melted and used as getters. The mass loss during melting was negligible. The as-melted buttons were homogenized at $1050^{\circ} \mathrm{C}$ in a $7 \times 10^{-6}$ Torr vacuum furnace for $72 \mathrm{~h}$ and then hot-rolled into plates of $5 \mathrm{~mm}$ thickness. Specimens with a dimension of $50 \mathrm{~mm} \times 50 \mathrm{~mm} \times 5 \mathrm{~mm}$ were carefully cut from these plates with a low-speed diamond saw. The cut specimens were annealed at $800^{\circ} \mathrm{C}$ in a vacuum furnace for $2 \mathrm{~h}$, and then quenched in water. The liquid/solid impingement erosion test was carried out according to the ASTM G73-93 and G76-95 standard test methods [24,25]. The set-up of the experiment is illustrated in Fig. 1. For the liquid/solid impingement erosion test, a high-speed water jet was ejected from a nozzle of $4 \mathrm{~mm}$ diameter, mixed with quartz sand of irregular shape, and then impinged on the tested specimen which was located $15 \mathrm{~mm}$ away from the nozzle. The impinged area on the tested specimen was about $25 \mathrm{~mm}^{2}$. Details of parameters for the impingement erosion test are presented in Table 2.

Table 2

Parameters of liquid/solid impingement erosion used in the present study

\begin{tabular}{ll}
\hline Impinged angle $\left({ }^{\circ}\right)$ & $15,30,45,60,75,90$ \\
Impinged speed $(\mathrm{m} / \mathrm{s})$ & $74.2,82.9,90.8,99.5$ \\
Impinged medium & Fresh water mixed with fresh quartz sand \\
Sand flow $(\mathrm{g} / \mathrm{min})$ & $2 \pm 0.5$ \\
Sand size $(\mu \mathrm{m})$ & $263 \sim 363$ \\
Erosion time $(\mathrm{h})$ & 2 \\
Test temperature $\left({ }^{\circ} \mathrm{C}\right)$ & 25 \\
\hline
\end{tabular}

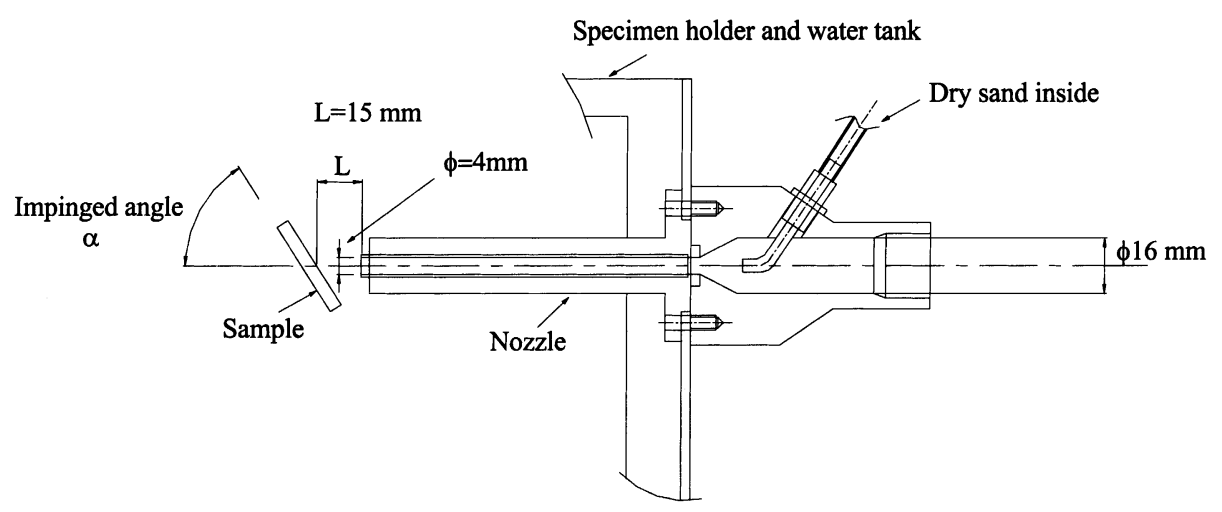

Fig. 1. Configuration of the impingement erosion testing equipment. 
According to Richardson [26], when the impinged particles are harder than the tested specimen and exceed a critical size, say $120-130 \mu \mathrm{m}$ for ductile materials and $100-125 \mu \mathrm{m}$ for brittle materials, the intrinsic properties of impinged particles will have no obvious effect on the impingement erosion rate. Meanwhile, impinged particles with irregular shape will cause serious erosion damage [27], which will shed light on the impingement erosion characteristics of the tested materials. Hence, the impinged particles used in this study, 263-363 $\mu \mathrm{m}$ quartz sand with irregular shape, can be considered as a controlled impingement parameter. Besides, these impinged particles were never used more than once.

The microstructures of eroded surfaces were studied by $\mathrm{X}$-ray diffraction (XRD) and scanning electron microscopy (SEM). XRD tests were carried out on an MAC-MXP-3 $\mathrm{X}$-ray diffractor using $\mathrm{Cu} \mathrm{K} \alpha$ radiation. The power was $40 \mathrm{kV} \times 30 \mathrm{~mA}$ and the $2 \theta$ scanning rate was $1 \%$ min. The surface morphologies were observed by a Topcon ABT-55 SEM. The surface hardness was measured with a micro-Vickers tester with a load of $100 \mathrm{~g}$ for $15 \mathrm{~s}$. For each specimen, the average hardness value was calculated from at least five test readings. The weight loss after impingement erosion was measured by using a precise electronic balance, with a weighing accuracy of \pm $0.01 \mathrm{mg}$.

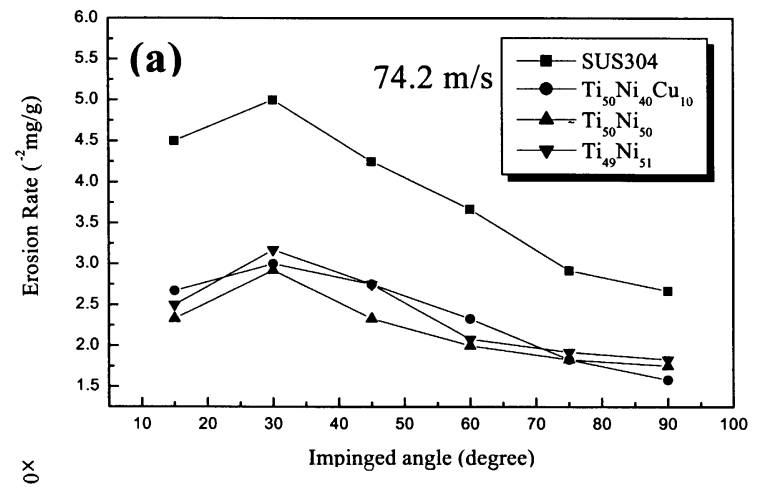

$\stackrel{\times}{\circ}$

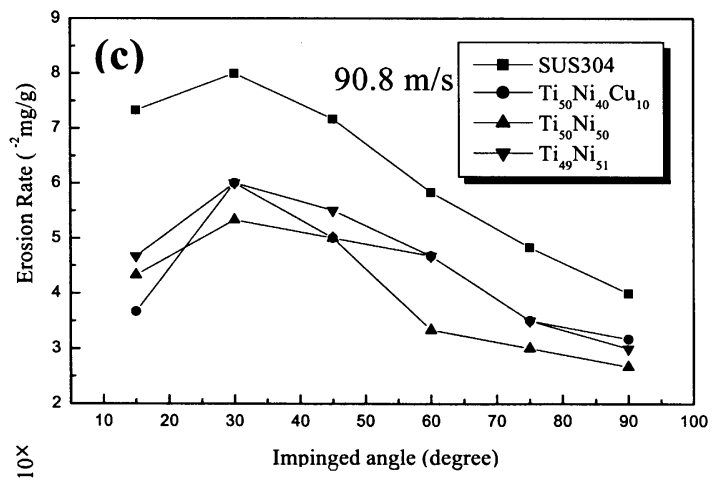

\section{Results and discussion}

\subsection{Factors influencing the liquid/solid impingement erosion characteristics of TiNi alloys}

Apart from the metallurgical properties, many testing parameters, e.g. the impinged angle, speed, and erosion time in this study, can also influence the impingement erosion characteristics of TiNi alloys.

\subsubsection{Impinged angle}

Fig. 2a-d show the erosion rates versus impinged angle for TiNi alloys and SUS304 stainless steel at various impinged speeds ranging from 74.2 to $99.5 \mathrm{~m} / \mathrm{s}$. The gravimetric erosion rate, commonly used to measure the erosion damage [28], is defined as the weight loss from the specimen surface per unit weight of impinged particles. In other words: erosion rate $(\mathrm{mg} / \mathrm{g})=$ weight loss of tested specimen (mg)/total weight of impinged particles (g).

As seen in Fig. 2a-d, maximum erosion rates appear at $30^{\circ}$ impinged angle for all TiNi alloys and SUS 304 stainless steel. This feature is typical for ductile materials [29]. For ductile materials, high-speed impingement at low impinged angle will enhance material removal by microcutting as a result of the oblique shear force [30], thus increasing the erosion rate. At high impinged angles, the normal compressive

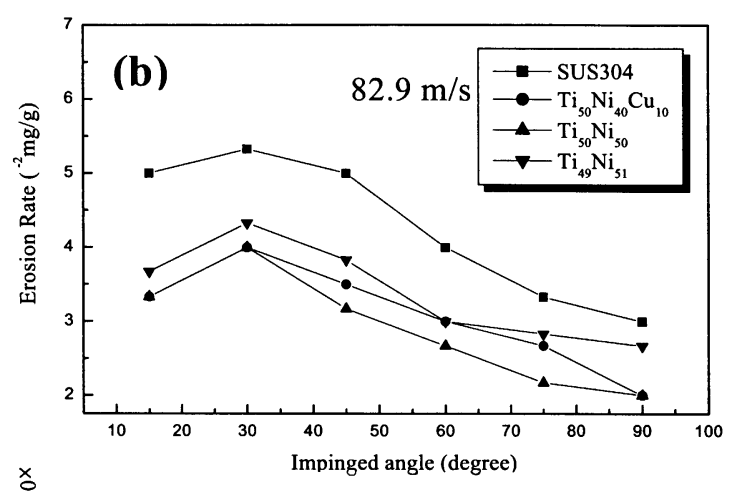

$\stackrel{\times}{\circ}$

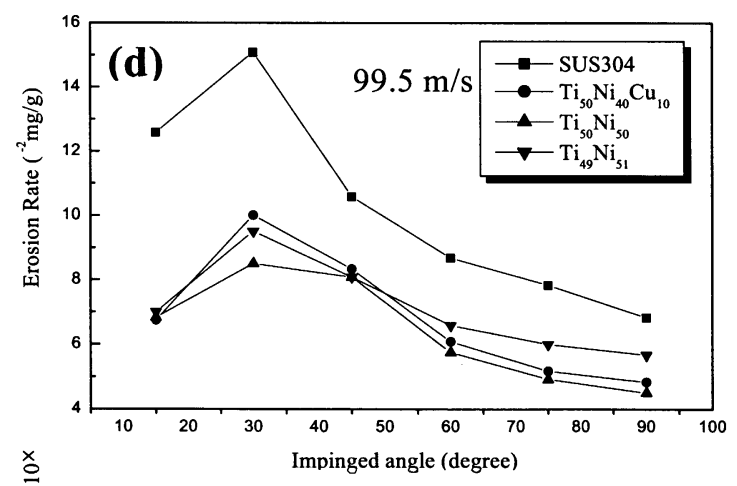

Fig. 2. Erosion rates vs. impinged angle for TiNi alloys and SUS304 stainless steel at various impinged speeds: (a) $74.2 \mathrm{~m} / \mathrm{s}$; (b) $82.9 \mathrm{~m} / \mathrm{s} ;$ (c) $90.8 \mathrm{~m} / \mathrm{s}$; (d) $99.5 \mathrm{~m} / \mathrm{s}$. 

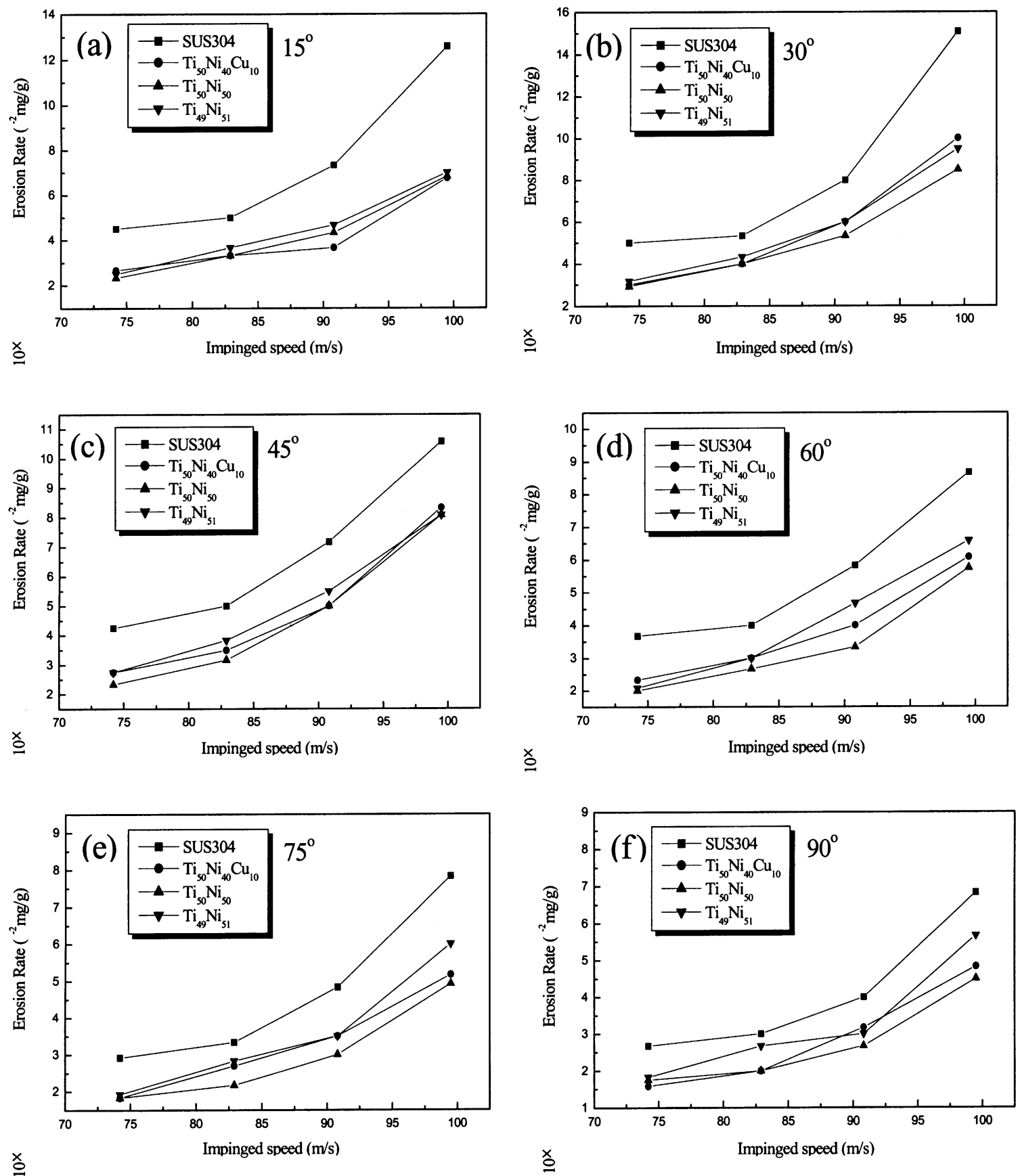

Fig. 3. Erosion rates vs. impinged speed for TiNi alloys and SUS304 stainless steel at various impinged angles: (a) $15^{\circ}$; (b) $30^{\circ}$; (c) $45^{\circ}$; (d) $60^{\circ}$; (e) $75^{\circ}$; (f) $90^{\circ}$.

force will mainly produce the accumulated damage from fatigue [31], shear localization [32], microforging and extrusion processes [33]. These processes could only produce slight erosion damage for ductile materials. As shown in Fig. 2a-d, TiNi alloys have lower erosion rates than SUS304 stainless steel. Their difference in erosion rates is more obvious at lower impinged angles. This indicates that $\mathrm{TiNi}$ alloys are more erosion-resistant than SUS304 stainless steel, especially, at low impinged angles. Meanwhile, it can also be found in Fig. $2 \mathrm{a}-\mathrm{d}$ that $\mathrm{Ti}_{49} \mathrm{Ni}_{51}, \mathrm{Ti}_{50} \mathrm{Ni}_{50}$, $\mathrm{Ti}_{50} \mathrm{Ni}_{40} \mathrm{Cu}_{10}$ alloys exhibit almost the same impingement erosion rate, although they have different crystal structures at testing temperature.

\subsubsection{Impinged speed}

Fig. 3a-f show the erosion rates as a function of impinged speed for TiNi alloys and SUS304 stainless steel at various impinged angles. In Fig. 3a-f, the erosion rates are found 
Table 3

Values of the $n$ exponents for TiNi alloys and SUS304 stainless steel impinged at various angles

\begin{tabular}{lllllll}
\hline Specimens & \multicolumn{7}{l}{ Impinged angle $\left({ }^{\circ}\right)$} \\
\cline { 2 - 7 } & 15 & 30 & 45 & 60 & 75 & 90 \\
\hline $\mathrm{Ti}_{49} \mathrm{Ni}_{51}$ & 2.65 & 2.81 & 2.67 & 2.56 & 2.42 & 2.44 \\
$\mathrm{Ti}_{50} \mathrm{Ni}_{50}$ & 2.89 & 2.84 & 2.77 & 2.52 & 2.45 & 2.09 \\
$\mathrm{Ti}_{50} \mathrm{Ni}_{40} \mathrm{Cu}_{10}$ & 2.60 & 2.59 & 2.17 & 2.68 & 2.98 & 2.12 \\
SUS304 & 2.42 & 2.33 & 2.59 & 2.29 & 2.49 & 2.00 \\
\hline
\end{tabular}

to increase substantially with the impinged speed. This can be reasonably expected because that higher impact force is acted on the impinged surface at higher impinged speed. The higher impact force will induce more severe damage during impingement erosion. Hence, the erosion rate should be higher at higher impinged speed. In Fig. 3a-f, the relation between the erosion rate $(\varepsilon)$ and the impinged speed $(V)$ is found to follow the expression $\varepsilon=k V^{n}$, where $k$ is a constant and $n$ is the exponent [29]. Table 3 presents the values of the $n$ exponent, which are calculated by the curve fitting method, for $\mathrm{Ti}_{49} \mathrm{Ni}_{51}, \mathrm{Ti}_{50} \mathrm{Ni}_{50}, \mathrm{Ti}_{50} \mathrm{Ni}_{40} \mathrm{Cu}_{10}$ and SUS304 stainless steel at various impinged angles. These $n$ exponents are between 2 and 3, as reported in the literature for ductile materials [29]. In Fig. 3a-f, TiNi alloys are also found to have lower erosion rates than SUS304 stainless steel. Their difference in erosion rates is more obvious at higher impinged speeds.

\subsubsection{Erosion time}

Fig. $4 \mathrm{a}$ and $\mathrm{b}$ show the cumulative weight loss versus erosion time for TiNi alloys and SUS304 stainless steel at $30^{\circ}$ and $90^{\circ}$ impinged angles, respectively, and with an impinged speed of $99.5 \mathrm{~m} / \mathrm{s}$. The cumulative weight losses versus erosion time for these alloys at other impinged angles and speeds show a similar variation tendency to those in Fig. 4a and b. In Fig. 4a and b, the cumulative weight losses are found to increase linearly with increasing erosion time for these four alloys. This indicates that the erosion mechanism for these alloys does not change noticeably, implying a steady erosion damage during the impingement process, regardless of the variation in impinged angle and speed.

\subsection{Surface hardness after impingement erosion}

Fig. 5 shows the surface hardness after impingement erosion for $2 \mathrm{~h}$ at an impinged speed of $99.5 \mathrm{~m} / \mathrm{s}$, versus impinged angle for TiNi alloys and SUS304 stainless steel. The impinged speed is found to have no obvious effect on the surface hardness. In Fig. 5, the surface hardness for these alloys is found to be raised after impingement erosion. This is due to work hardening induced by the liquid/solid impingement. Meanwhile, the work-hardening effect is more obvious at higher impinged angles. This is reasonable because the normal compressive force impacting on the
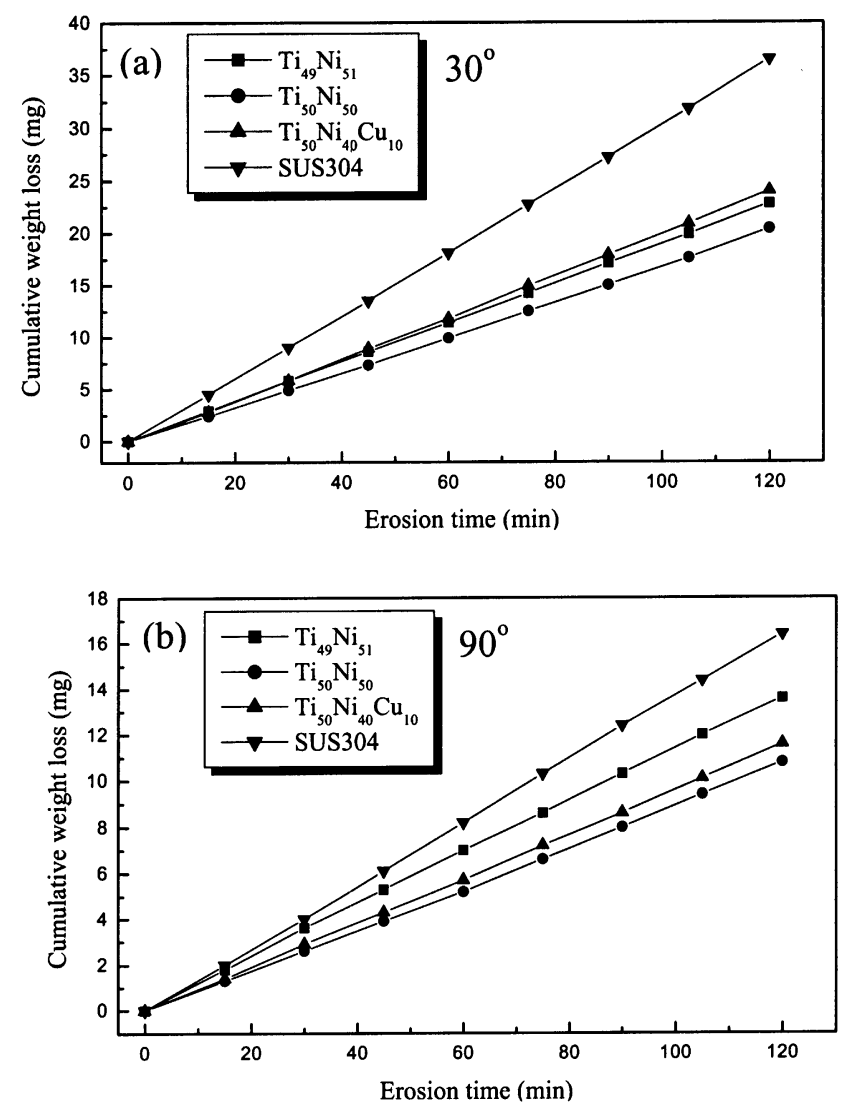

Fig. 4. Cumulative weight losses vs. erosion time for TiNi alloys and SUS304 stainless steel after impingement at (a) $30^{\circ}$ and (b) $90^{\circ}$ angles, and with an impinged speed of $99.5 \mathrm{~m} / \mathrm{s}$.

surface is higher at higher impinged angles and will induce greater and more extensive plastic deformation, and hence enhance the work hardening. In Fig. 5, it can be seen that the surface hardness exhibits a rapid increase at around $30-40^{\circ}$ impinged angle. This may be ascribed to the change in deformation behavior. At low impinged angles, the impact force of impinged particles is mostly used to plough out the material. Though local strains may be introduced during this cutting process, only slight plastic deformation occurs on the impinged surface and hence the work hardening is low. However, if the impinged angle is greater than $30^{\circ}$, the impact force of impinged particles is mostly used to induce plastic deformation, resulting in a high work-hardening rate.

As mentioned in Section 1, the work-hardening characteristics of a material will have important influence on the erosion resistance. In other words, materials with high work-hardening rates would exhibit better erosion resistance [18-22]. In our previous study [16], the stress-strain curves of TiNi alloys exhibit a work-hardening rate higher than that of SUS304 stainless steel. This indicates that TiNi alloys will have better erosion resistance than SUS304 stainless steel, as evidenced by the experimental results shown in Figs. 2-4. 


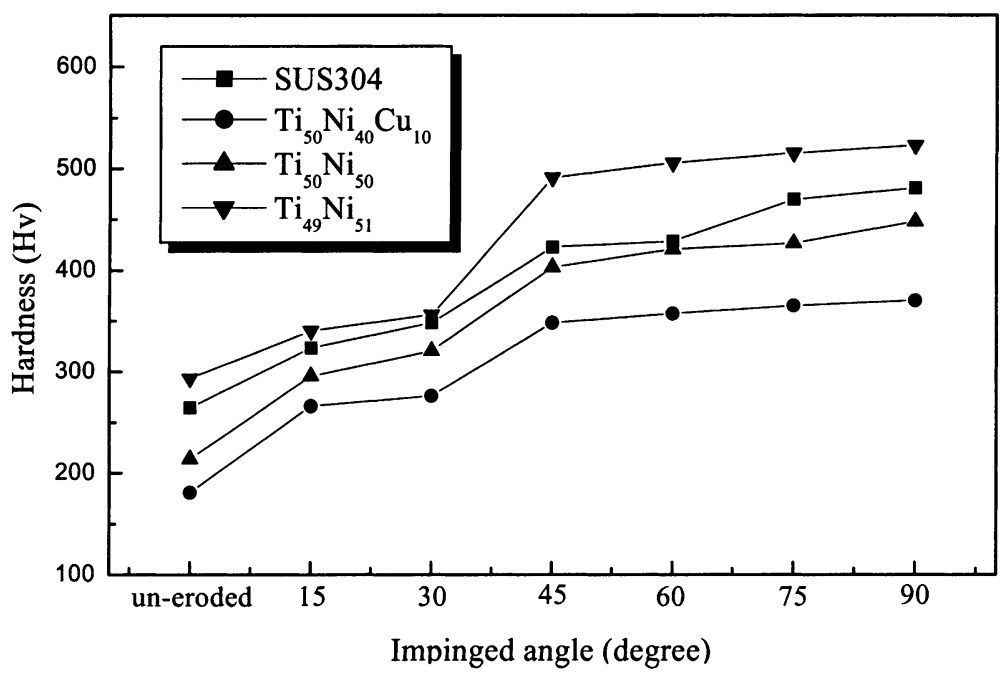

Fig. 5. Surface hardness after impingement erosion of $2 \mathrm{~h}$ at an impinged speed of $99.5 \mathrm{~m} / \mathrm{s}$, vs. impinged angle for TiNi alloys and SUS304 stainless steel.
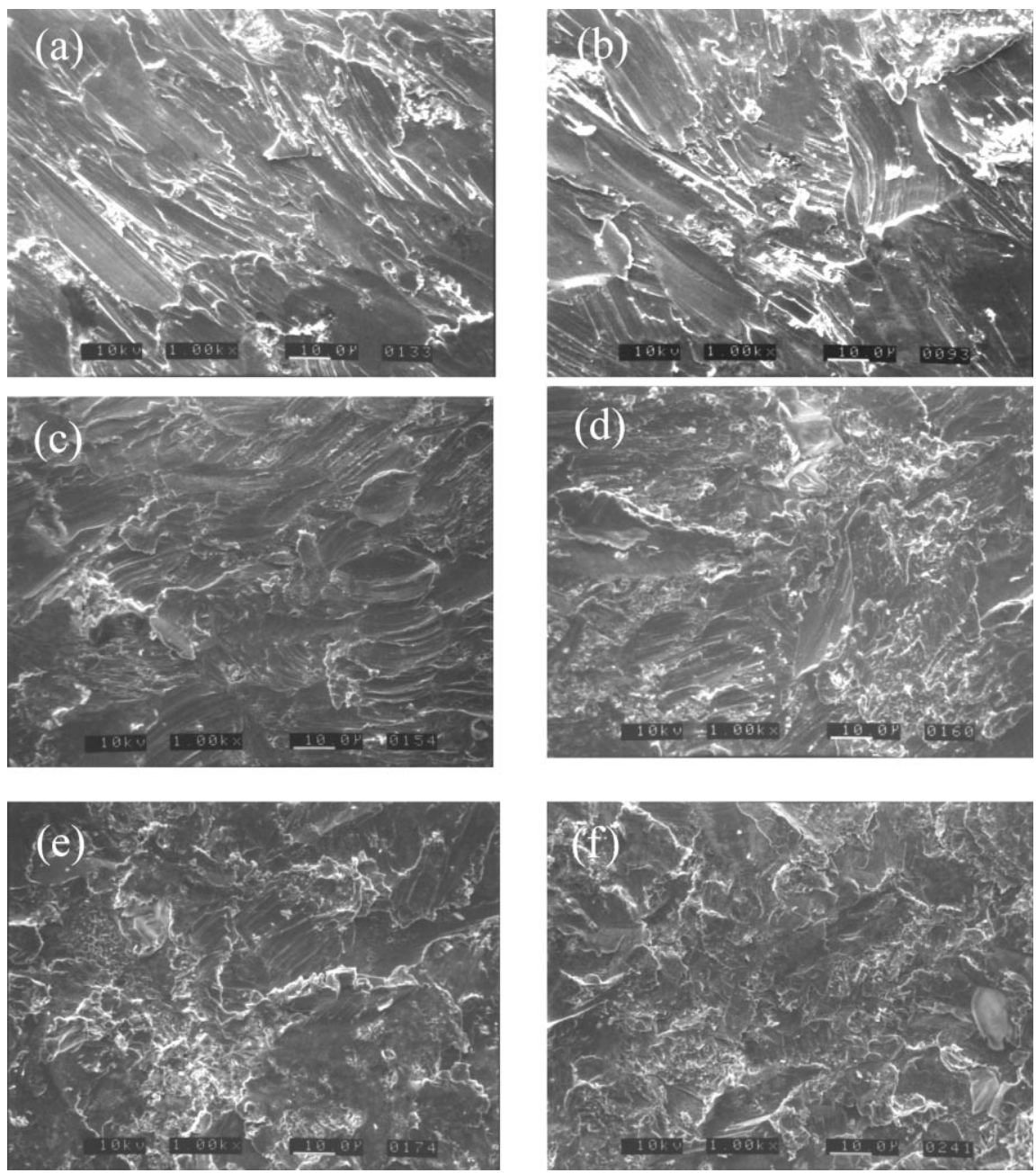

Fig. 6. Typical scanning electron micrographs of impinged surfaces for TiNi alloys and SUS304 stainless steel, subjected to impingement erosion of $2 \mathrm{~h}$ at impinged speed of $99.5 \mathrm{~m} / \mathrm{s}$ and various impinged angles: (a) $15^{\circ}$; (b) $30^{\circ}$; (c) $45^{\circ}$; (d) $60^{\circ}$; (e) $75^{\circ}$; (f) $90^{\circ}$. 


\subsection{Morphologies of impinged surfaces}

The morphologies of impinged surfaces for TiNi alloys and SUS304 stainless steel are similar due to their ductile behavior. Fig. 6a-f, are typical SEM micrographs of the impinged surfaces for these alloys subjected to impingement erosion of $2 \mathrm{~h}$ at impinged speed of $99.5 \mathrm{~m} / \mathrm{s}$ and various impinged angles. In Fig. 6a-f, two distinct morphologies can be found for these alloys impinged at various angles. As shown in Fig. 6a-c, for impingement at low angles, the surface morphologies exhibit lots of long furrows and ridges, which are ploughed out by the impinged particles. This ploughing mechanism will have a significant material removal rate, that is a high erosion rate, as shown in Fig. 2. At high impinged angles, lots of overlapping and irregular concavities can be seen in the surface morphologies, as shown in Fig. 6d-f. It is because at high impinged angles, the impact force of impinged particles is mostly used to induce plastic deformation, namely, microforging and extrusion. This combined deformation of microforging and extrusion will produce indented concavities and protruding thin platelets. These protruding thin platelets will then be partially impinged off by the subsequent impinged particles. Therefore, after continuous impingement, the surface morphologies will finally consist of many overlapping irregular concavities and residual protruding thin platelets attached onto the nearby surface. In fact, these impinged surface morphologies are consistent with those reported for ductile materials $[33,34]$.

\subsection{Deformation phenomena during impingement erosion in TiNi alloys}

Deformed structures resulted from the liquid/solid impingement can be clearly seen from the XRD results shown in Fig. $7 \mathrm{a}-\mathrm{c}$ for the $\mathrm{Ti}_{49} \mathrm{Ni}_{51}, \mathrm{Ti}_{50} \mathrm{Ni}_{50}$ and $\mathrm{Ti}_{50} \mathrm{Ni}_{40} \mathrm{Cu}_{10}$ alloys, respectively. In Fig. 7a, the solution-treated $\mathrm{Ti}_{49} \mathrm{Ni}_{51}$ alloy has a B2 structure. After impingement, $\mathrm{Ti}_{49} \mathrm{Ni}_{51}$ alloy exhibits the B2 and B19' structures, although the XRD peaks are broadened. This indicates that the stress-induced martensitic (SIM) transformation from B2 structure occurs as a result of the impingement of high-speed particles. This behavior is known as "pseudoelasticity" [2,3]. After impingement, the crystal structures are slightly distorted by the residual strain. In Fig. $7 b$, the solution-treated $\mathrm{Ti}_{50} \mathrm{Ni}_{50}$ alloy exhibits the typical martensite structure. But after impingement, an obvious B2 structure can be observed in Fig. 7b. It reveals that the stress-induced parent phase (SIP) can be introduced during the impingement of high-speed particles. This unusual behavior has been reported in previous studies [12,35], where the SIP can also be introduced by cold-rolling and sliding wear because of the complex stress distribution. Lattice softening, which occurs around the transformation temperatures for TiNi alloys, can promote shear transformations by thermal or mechanical driving force $[36,37]$. In the present study, the impinged medium temperature (about $25^{\circ} \mathrm{C}$ ) is quite near the As temperature
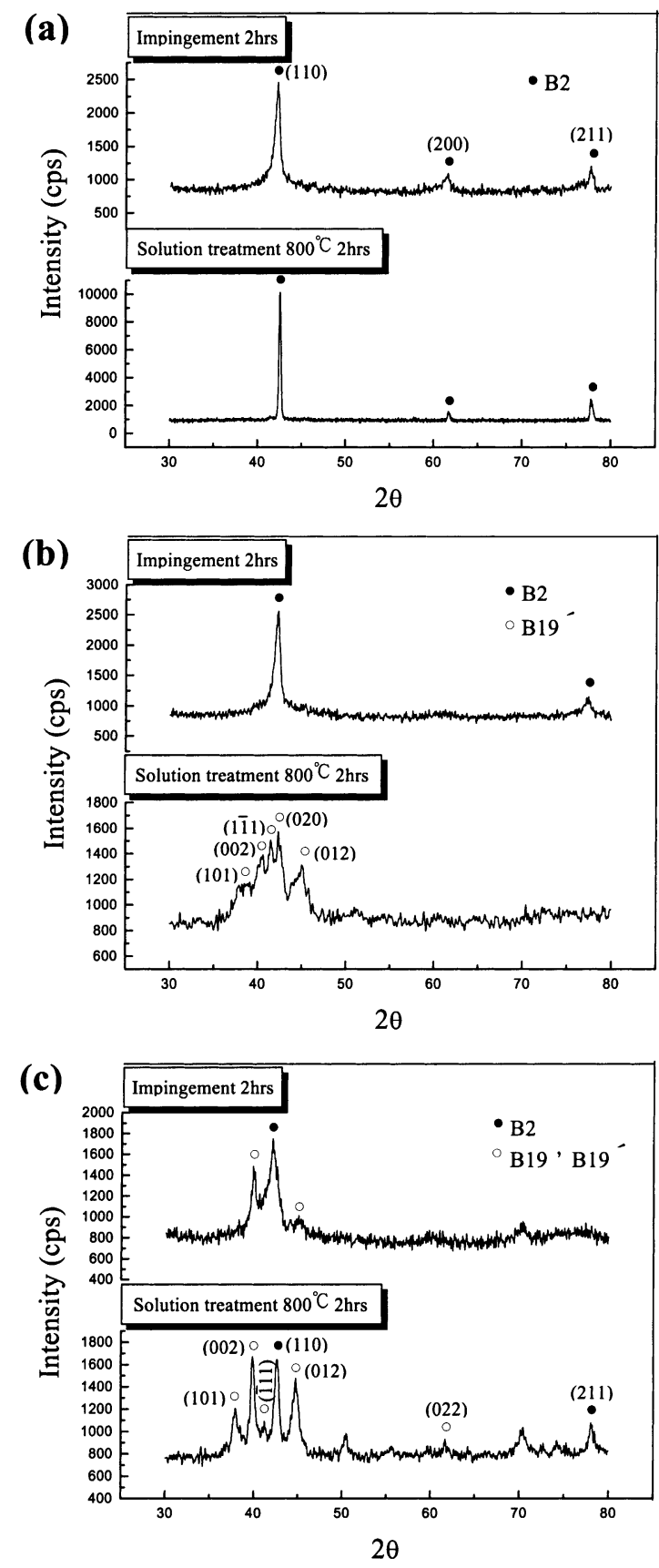

Fig. 7. X-ray diffraction of impinged surfaces for (a) $\mathrm{Ti}_{49} \mathrm{Ni}_{51}$; (b) $\mathrm{Ti}_{50} \mathrm{Ni}_{50}$ and (c) $\mathrm{Ti}_{50} \mathrm{Ni}_{40} \mathrm{Cu}_{10}$ alloys, subjected to impingement erosion of $2 \mathrm{~h}$ at impinged speed of $99.5 \mathrm{~m} / \mathrm{s}$ and impinged angle of $90^{\circ}$.

(about $60^{\circ} \mathrm{C}$ ). Hence, as shown in Fig. 7b, the SIP can be introduced on the impinged surface by the impact stress of high-speed particles. In Fig. 7c, the solution-treated $\mathrm{Ti}_{50} \mathrm{Ni}_{40} \mathrm{Cu}_{10}$ alloy has coexisting structures of B2 and martensite phases. After impingement, the main XRD peaks only exhibit the existence of B2 phase and a preferential ( $\left.\begin{array}{lll}0 & 0 & 2\end{array}\right)$ martensite structure. The XRD intensity of B2 phase is found to be increased after impingement. This implies that the SIP can also be introduced during the liquid/solid 
impingement for $\mathrm{Ti}_{50} \mathrm{Ni}_{40} \mathrm{Cu}_{10}$ alloy. Meanwhile, under the impingement of high-speed particles, the martensite variants can be reoriented to a preferred orientation, say $\left(\begin{array}{lll}0 & 0 & 2\end{array}\right)$ plane in Fig. 7c. These deformation phenomena of TiNi alloys have important contributions to their impingement erosion characteristics and will be discussed in the next section.

\subsection{Effects of thermoelastic martensitic transformations on the liquid/solid impingement erosion of TiNi alloys}

It is important to establish the erosion characteristics of TiNi alloys and understand why they have high liquid/solid erosion resistance despite their low hardness. The unusual erosion characteristics are believed to be related to their thermoelastic behavior and work-hardening characteristic. During the impingement of high-speed particles on the TiNi B2 parent phase, the impact strain will be mostly transformed to pseudoelastic strain as a result of the formation of stress-induced martensite (SIM). This SIM will resume its parent phase after the relief of impact load. In other words, the SIM formation and pseudoelastic behavior will accommodate elastically the impact strain and partially relieve the impact load. This feature will improve the impingement erosion resistance of the TiNi B2 phase. For the impingement erosion of TiNi martensite, partial impact energy has been annihilated by variant accommodation and/or SIP formation. The martensite variants can accommodate the impact strain due to the easy movement of twin boundaries, and the SIP can exhibit the pseudoelastic behavior. All these phenomena will have important contributions to the impingement erosion resistance of TiNi alloys. In addition, some fatigue cracks may occur as a result of the repeated impact of high-speed particles [30], especially at high impinged angles. The fatigue crack tips can be blunted and stabilized by the variant accommodation and/or pseudoelasticity. For most metals and alloys, plastic deformation and/or crack propagation release the strain energy of crack tips. However, for TiNi alloys, the variant accommodation and/or pseudoelasticity will absorb partial impact energy to be stored in the martensite variants and/or SIM. These features will stabilize the fatigue crack tips and hinder crack propagation, hence improving the impingement erosion characteristics of TiNi alloys. If the impact exceeds the reversible transformation strain associated with the variant accommodation and/or pseudoelasticity, up to $8 \%$ for TiNi alloys, then high work hardening occurs, thus resisting the impingement erosion.

\section{Conclusions}

The erosion characteristics of three TiNi shape memory alloys and SUS304 stainless steel using the liquid/solid impingement will result in the following conclusions.

1. More resistant TiNi alloys and less resistant SUS304 stainless steel exhibit ductile behavior and the maximum erosion has observed at $30^{\circ}$ as reported in the literature for ductile materials. The surface morphologies exhibit many long furrows and ridges at low impingement angles which have been observed by other investigators for ductile materials. The exponent in the relation $\varepsilon=k V^{n}$ varied between 2 and 3 for impingement angles between 15 and $90^{\circ}$.

2. Work hardening of surface is observed on the surface of all tested materials. The work hardening layer and thin platelet formation increase with angle of impingement.

3. The SIM formation and pseudoelastic behavior of TiNi B2 phase, and variant accommodation and SIP formation of TiNi martensite, will partially relieve the impact load and accommodate the impact strain elastically. These features and work hardening will also stabilize the fatigue crack tips and stall the crack propagation, thus improving the impingement erosion resistance of TiNi alloys.

\section{Acknowledgements}

The authors gratefully acknowledge the financial support of this research by the National Science Council (NSC), Republic of China, under Grants NSC87-TPC-E002-022 and NSC88-2216-E002-012. The authors also express their sincere appreciation to Profs. J.L. He and K.M. Lin, Department of Materials Science, Feng Chia University, Taichung, Taiwan, for their kind assistance.

\section{References}

[1] C.M. Jackson, H.J. Wagner, R.J. Wasilewski, NASA Report SP-5110 (1972).

[2] G.D. Sandrock, A.J. Perkins, R.F. Hehemann, Metall. Trans. A 2 (1971) 2769.

[3] S. Miyazaki, T. Imai, Y. Igo, K. Otsuka, Metall. Trans. A 17 (1986) $115-120$.

[4] K.N. Melton, O. Mercier, Acta Metall. 27 (1979) 137-144.

[5] Y. Oshida, S. Miyazaki, Corr. Eng. 40 (1991) 1009-1025.

[6] L.S. Castleman, S.M. Motzkin, in: D.F. Williams (Ed.), Biocompatibility of Clinical Implant Materials, CRC Press, Boca Raton, FL, 1981, pp. 129-154.

[7] H.C. Lin, S.K. Wu, M.T. Yeh, Metall. Trans. A 24 (1993) 2189-2194.

[8] H.C. Lin, S.K. Wu, Y.C. Chang, Metall. Mater. Trans. A 26 (1995) 851-858.

[9] J.L. Jin, H.L. Wang, Acta Metall. Sinica 24A (1988) 66-69.

[10] D.Y. Li, Scripta Metall. 34 (1996) 195-200.

[11] P. Clayton, Wear 162-164 (1993) 202-210.

[12] H.C. Lin, H.M. Liao, J.L. He, K.C. Chen, K.M. Lin, Metall. Mater. Trans. A 28 (1997) 1871-1877.

[13] Y. Suzuki, T. Kuroyanagi, FAEDIC-NT, Titanium Zirconium 27 (1979) 67-73.

[14] Y. Shida, Y. Sugimoto, Wear 146 (1991) 219-228.

[15] R.H. Richman, W.P. McNaughton, J. Mater. Eng. Perfor. 6 (1997) 633-641.

[16] S.K. Wu, H.C. Lin, C.H. Yeh, Wear 244 (2000) 85-93.

[17] E. Nakao, S. Hattori, in: Proceedings of the Japanese Society on Mechanical Engineering, Vol. 64, 1998, pp. 2555-2560 (in Japanese).

[18] A. Ball, Wear 91 (1983) 201-207. 
[19] C.J. Heathcock, B.E. Protheroe, A. Ball, in: Proceedings of the 5th International Conference on the Strength of Metals and Alloys, Pergamon Press, Oxford, 1979, pp. 219-224.

[20] A.W.J. de Gee, Wear 81 (1982) 373.

[21] W.J. Salesky, G. Thomas, Wear 75 (1982) 21.

[22] C. Allen, A. Ball, B.E. Protheroe, Wear 74 (1981/1982) 287.

[23] R.H. Richman, A.S. Rao, D. Kung, Wear 157 (1992) 401407.

[24] ASTM G73-93, Liquid Impingement Erosion Testing, ASTM, 1993.

[25] ASTM G76-95, Conducting Erosion Tests by Solid Particle Impingement Using Gas Jets, ASTM, 1995.

[26] R. Richardson, Wear 10 (1967) 291.

[27] S.S. Aptehar, Wear of Materials, ASME, New York, 1985, pp. 677-686.
[28] I.M. Hutchings, R.E. Winter, J.E. Field, Proc. R. Soc. London A 348 (1976) 379-392.

[29] K.Z. Gahr, Microstructure and Wear of Material, Tribology Series 10, Elsevier, New York, 1987.

[30] I. Finnie, D.H. McFadden, Wear 48 (1978) 181-190.

[31] I.M. Hutchings, Wear 70 (1981) 269-281.

[32] G. Sundararajan, P.G. Shewmon, Wear 84 (1983) 237-258.

[33] R. Bellman, A. Levy, Wear 70 (1981) 1-27.

[34] C.T. Morrison, R.O. Scattergood, Wear 111 (1986) 1-13.

[35] H.C. Lin, S.K. Wu, Metall. Trans. A 24 (1993) 293-299.

[36] O. Mercier, K.N. Melton, G. Gremaud, J. Hagi, J. Appl. Phys. 41 (1980) 1833-1834.

[37] A.I. Lotkov, A.V. Kuznetsov, V.N. Griskov, A.A. Botaki, in: Proceedings of the International Shape Memory Alloy Symposium, Gulin, China, 1986, pp. 153-158. 